\title{
JUSTIÇA NA RELIGIÃO E CONFORTO NO SISTEMA JUDICIÁRIO: RELAÇÕES POLÍTICO-RELIGIOSAS ENTRE FAMILIARES DE VÍTIMAS DA VIOLÊNCIA URBANA NO RIO DE JANEIRO
}

\author{
Amanda Gomes Pereira ${ }^{1}$
}

RESUMO: O presente trabalho tem como objetivo descrever as relações político-religiosas estabelecidas por familiares de vítimas da violência na cidade do Rio de Janeiro, através das interfaces entre espiritismo e política na construção dos discursos sobre sofrimento social. A busca desses familiares por justiça nos casos dos seus filhos transformados em causa pública se une à peregrinação desses pais e mães aos centros espíritas atrás das psicografias dos filhos falecidos. A manutenção da comunicação, além da permanência do contato afetivo, é vista também como a possibilidade de esclarecer os acontecimentos que rondaram as mortes de seus filhos e, desse modo, compreender os fatos ao redor delas, utilizando as psicografias como provas possíveis nos julgamentos jurídicos. Os diálogos entre o sistema judiciário e a filosofia espírita promovidos por esses familiares permitem compreender as ações desses familiares na luta por justiça, conforto e adesão subjetiva à Cultura da Paz.

PALAVRAS-CHAVE: Espiritismo. Sistema Judiciário. Psicografias. Violência Urbana

Recebido em: setembro 2013

Aceito em: abril 2014

Para citar este artigo:

PEREIRA, Amanda; "Justiça Na Religião E Conforto No Sistema Judiciário: Relações Político-Religiosas Entre Familiares De Vítimas Da Violência Urbana No Rio De Janeiro." In: Revista Intratextos, 2014, vol 5, no 1, p. 29-45. DOI: http://dx.doi.org/10.12957/intratextos.2014.10517.

\footnotetext{
${ }^{1}$ Docente UFMA e doutoranda PPCIS/UERJ. Email: gomespereira_amanda@yahoo.com.br
} 
Reencontramos nossos amores num próximo luar. Mesmo sem lagoa, mesmo sem noite, mesmo sem Lua. Dentro da luz, eternos, eles regressam, roupa flutuando na corrente de um rio.

(Mia Couto-Antes de nascer o mundo)

As relações político-religiosas estabelecidas por familiares vítimas da violência no Rio de Janeiro, bem como as diferentes percepções de justiça - espiritismo e judiciário - que se entrelaçam nas narrativas que surgem dessas relações são o objeto de discussão deste artigo. Os dados apresentados aqui fazem parte da minha pesquisa de campo em que tive a oportunidade de participar ativamente do cotidiano de famílias vítimas da violência urbana na cidade do Rio de Janeiro, inseridas em uma rede espírita. A partir dessa convivência recorrente, desde 2010, participei de reuniões e atividades políticas, assim como das sessões espíritas dos médiuns Rogério H. Leite e Fábio Figueiredo - acompanhei as sessões do médium Rogério Leite, na cidade do Rio de Janeiro, no ano de 2010, e frequentei as sessões do GEC nos anos 2012 e 2013. Para este artigo, recorri ainda a outras fontes como jornais, revistas e sítios da internet para ter acesso aos conteúdos jornalísticos produzidos pela mídia nacional sobre espiritismo, dons mediúnicos e a relação com o sistema judiciário. Pesquisei a base de dados da Biblioteca Nacional para acessar as edições dos principais jornais brasileiros, no período próximo da data da morte do menino João Hélio. Desse modo, para desenvolver o tema central desse artigo, mesclei fontes documentais e pesquisa de campo realizada junto a uma rede espírita de familiares vítimas da violência urbana.

Em uma casa na Rua Bom Pastor, na Tijuca, com janelas amplas e portas estreitas, entre um salão grande, salas pequenas e uma pequena copa aconchegante, se encontram os frequentadores do Grupo Espiritualista Consciência. Pessoas das mais diferentes regiões da região metropolitana do Rio de Janeiro vão ao local em busca das mensagens dos entes queridos, de um passe, de uma cura espiritual ou simplesmente de uma palavra consoladora e transformadora. São esses os trabalhos desenvolvidos por este Centro Espírita segundo definição de seus colaboradores, frequentadores, médiuns e amigos. Como sempre gosta de destacar o médium Fábio Figueiredo: “- Aqui se faz amigos, sustentados nos dois planos". 
O meu primeiro contato com esse Centro Espírita foi quando, no aniversário de uma das amigas de duas mães, a "Maroca" - amiga da Zoraide ${ }^{3}$ e da Francilene ${ }^{4}$-, elas me narraram a experiência da psicofania $^{5}$ vivenciada pela Francilene nesse centro. Zoraide começou a frequentá-lo e, um dia, recebeu uma mensagem de que o Thiago, filho da Francilene, estava pedindo para que ela comparecesse ao centro. Segundo palavras da Francilene - "Eu não sabia que ainda havia tantas lágrimas dentro de mim, achei que já havia chorado tudo pelo meu filho". Segundo ela, foi emocionante ter a possibilidade de abraçar o filho através do corpo do médium enquanto este repassava as mensagens ditas pelo Thiago naquele exato momento através do dom mediúnico da psicofania. Neste dia também, Zoraide relatou-nos a experiência de receber a primeira psicografia que reconhecia como sendo verdadeiramente de sua filha. Em todas essas situações de relatos do recebimento de mensagens ou da participação em sessões mediúnicas, a descrição dos detalhes particulares presentes nas mensagens sempre se destaca nas rodas de conversa. São descrições íntimas que, para os familiares dos entes desencarnados, conhecidos apenas por pessoas próximas do núcleo familiar. Eles também narram momentos de grande privacidade, da intimidade familiar, segundo esses relatos, divididos apenas entre, no caso específico que estudo, mães, pais, filhos e filhas.

\footnotetext{
${ }^{2}$ Os nomes e apelidos que utilizo neste texto reproduzem a forma como essas pessoas se nomeiam e se referem umas as outras tanto na presença, como em falas em que uma delas esteja ausente. Por serem pessoas que convivem há anos, o tratamento e a forma como se referem uns aos outros são informais, e, ao escrever este artigo, decidi optar pela maneira como eles se nomeiam e definem suas relações.

${ }^{3}$ Embora não seja a prática comum em trabalhos como este, os nomes das pessoas são verdadeiros, citados com o consentimento desses familiares, no intuito de dar voz à luta desses pais e mães na busca por visibilidade das histórias de seus filhos e filhas. Meu contato com o grupo de pais e mães de policiais civis e militares assassinados no Rio de Janeiro/ RJ aconteceu em 2009, quando participei de uma pesquisa realizada pela Universidade Federal de Juiz de Fora sobre o processo de implementação da Política Pública "Mulheres da Paz". Os depoimentos de familiares presentes neste texto são de pais e mães vítimas da violência na cidade do Rio de Janeiro, das mais diferentes fontes.

${ }^{4}$ Zoraide Vidal Fernandes é mãe de Ludmila Maria Fernandes Fragoso, policial civil assassinada na favela Parque Estrela, Duque de Caxias, após ser assaltada na Avenida Brasil. Ela foi violentada, teve ser corpo quebrado em diversas partes e o carro em que estava foi incendiando com o corpo dela dentro. Francilene Pinheiro é mãe de Thiago Pinheiro Castro, policial civil, assassinado com um tiro nas costas em Cascadura, Rio de Janeiro, após ter seu carro assaltado. Nos dois casos, a identificação da profissão de policial durante o assalto foi a justificativa dada para o assassinato das vítimas.

${ }^{5}$ São muitos os dons mediúnicos. Assim como um mesmo dom pode se manifestar de diversas formas. Nas sessões que acompanhei, o dom da psicofania se manifestava de duas formas distintas. Nas sessões do projeto Cartas Consoladoras, o médium que tinha esse dom apenas reproduzia as mensagens que lhe eram passadas. Não mudava de voz, suas expressões corporais permaneciam as mesmas, era como se ele tivesse dando um recado. Já nas sessões de psicofania do GEC, o médium mudava seus gestos e sua performance buscava reproduzir a presença física da pessoa, criando a impressão de que o familiar se comunicava com o seu parente falecido através do corpo do médium .
} 
O modo carinhoso como um se referia ao outro, extremamente particular e único para esses pais, impossível, para eles, de o médium ter conhecimento se tornam indícios da sobrevivência dos filhos em outro plano - o espiritual. Em busca dessas mensagens "consoladoras" - como as definia outro médium, o Rogério H. Leite, do qual também participei de algumas de suas sessões -, os pais empreendem uma verdadeira peregrinação de centro a centro na expectativa de receber as cartas de seus filhos. Como destacou Fábio, em uma de nossas conversas, a procura ávida desses familiares pelas mensagens dos seus filhos e filhas faz com que eles se desloquem de centro em centro, substituindo as mensagens pela presença dos filhos e filhas o que, segundo ele, apesar de compreensível, não é o objetivo das mensagens psicografadas. Segundo o médium, o mecanismo de envio das mensagens ocorre a partir das forças desencarnadas. Como muitos espíritas costumam repetir, palavras de Chico Xavier: “"- O telefone toca de lá para cá, e não o contrário”. Por mais que a pessoa fique chateada quando não recebe a mensagem, e eu compreendo a dor dela, a minha mediunidade é inconsciente e não determino quando e para quem as mensagens virão", destacou o médium Fábio Figueiredo.

As mensagens, segundo ele, devem servir para as pessoas superarem suas dores, seus traumas e encontrarem caminhos de perdão e superação, compreendendo que a vida para o espiritismo está inserida em uma engrenagem muito maior de encarnações do que a vida material, presente e atual. As cartas são o meio das pessoas saberem que os seus entes queridos desencarnados permanecem vivos, em outro lugar, e não como uma busca de reprodução da existência material desses familiares com seus filhos - no caso específico da minha pesquisa. As mensagens promovem o perdão, a superação, o abandono do sentimento de vingança. Em alguns casos, contrariando as expectativas de alguns familiares que procuram compreender detalhes não esclarecidos durante a investigação criminal sobre o assassinato dos filhos e filhas através dessas mensagens. "Se as pessoas buscam avidamente saber de alguns detalhes que as psicografias não trazem, elas deveriam compreender que, talvez, não é para que elas saibam de determinados fatos”, ressalta o médium Fábio Figueiredo.

É a partir desse complexo emocional e simbólico do perdão, da aceitação, da superação e da caridade que se fundamenta o espiritismo vivenciado e praticado neste centro, ancorado na agência dos familiares das pessoas mortas que se organizam em multidões em 
busca de alguma mensagem psicografada. Os ensinamentos da caridade, do perdão como mecanismos de salvação e o agenciamento dessas famílias na manutenção da comunicação com seus familiares que fundamentam as sessões de psicografias das quais participei durante a pesquisa. Os centros ficam cheios de gente que se aperta, se ajeita em um pequeno espaço na esperança de, naquela sessão, ser agraciada com as mensagens - sejam pequenos recados ou cartas extensas.

No centro Grupo Espiritualista Consciência são cerca de 300 pessoas que se apertam em todos os cômodos existentes na casa durante as sessões, mesmo sabendo que apenas um número de 10 a 20 psicografias serão lidas. A utilização da internet e de outros meios de comunicação, no caso específico desse centro, contribui para que alguns presentes saibam de antemão que receberam mensagens. A dinâmica de recebimento de mensagens desse centro funciona da seguinte maneira, a pessoa visita o centro e coloca seu nome e o nome dos entes queridos desencarnados em uma caixa - específica para quem quer receber mensagens - com os números pessoais de telefone para contato. O Grupo no Facebook G.E.C também é utilizado pelo médium Fábio Figueiredo e pelos colaboradores do centro para entrarem em contato com os familiares cujos entes desencarnados enviaram mensagens. Esses familiares são chamados a comparecer a determinada reunião de psicografias. A página do facebook https://www.facebook.com/geconsciencia?fref=ts é utilizada também para as pessoas deixarem os nomes das pessoas desencarnadas das quais elas querem receber mensagens. Como consta na própria descrição da página: “Olá Amigos, por determinação da Espiritualidade Maior, esta página destina-se EXCLUSIVAMENTE para pedidos de psicografias à distância”.

O Grupo Espiritualista Consciência (GEC) surgiu acerca de quatro anos. Sua fundação é fruto da organização de famílias que conheciam anteriormente os dons mediúnicos do médium Fábio Figueiredo e resolveram alugar uma sede para o desenvolvimento das atividades mediúnicas e estudos da doutrina espírita. A administração do espaço, até o ano 2013, estava a cargo dessas famílias que se dividiam na manutenção, organização do espaço e planejamento das atividades. Pessoas que passaram a frequentar o centro após a fundação passaram a contribuir na realização das atividades - se juntando a esse grupo inicial -, tais como: se responsabilizarem pela biblioteca ou cantina. $\mathrm{O}$ médium contribui com as atividades realizadas e preside as sessões de psicografia. Porém, não está diretamente ligado a administração do espaço. Ele coordena ainda as sessões de desenvolvimento dos médiuns 
iniciantes que frequentam o centro. A escolha dos temas das palestras, dos palestrantes e das atividades é fruto de decisão coletiva. A única decisão arbitrária tomada sem a consulta do grupo é sobre as sessões de psicografia e psicofania que estão submetidas às decisões das entidades espirituais.

Apesar dos múltiplos canais de comunicação de mídia utilizados pelo médium Fábio Figueiredo e pelos colaboradores do GEC - todas as pessoas que trabalham no centro estão ali exercendo trabalho voluntário -, há períodos de recesso das sessões de psicografias. Essas, que no começo ocorriam todas as terças-feiras, passaram a ocorrer esporadicamente. Segundo o médium, por exigências espirituais, mas também pelo desgaste que essas sessões causam nele. Como ressaltou: “- Vivo doente. De três em três meses estou tendo algum tipo de infecção". Além disso, o grupo que trabalha mais ativamente no centro achou melhor que cursos e palestras, voltados para o estudo dos ensinamentos espíritas, fossem mais frequentes.

Quando as sessões ocorriam todas as terças-feiras, os lugares no interior da casa eram disputadíssimos. As pessoas tinham que chegar por volta das três horas da tarde para pegarem uma senha. Depois elas ficavam esperando até às $18 \mathrm{hs}$ quando a casa abria e, aí, descobriam se a senha garantia um lugar para elas se sentarem. Se não, elas ficariam em pé até às $23 \mathrm{hs,}$ quando termina a sessão, em pé. Os desgastes físico e emocional dessas sessões são enormes. No entanto, na outra terça-feira, as pessoas estavam lá, novamente, enfrentando os mesmos esgotamentos na esperança de receberem as mensagens de seus entes queridos desencarnados.

Diferentes das sessões mediúnicas, nas outras é possível chegar próximo do horário marcado para iniciar a sessão, por volta das $20 \mathrm{hs,} \mathrm{encontrar} \mathrm{um} \mathrm{lugar} \mathrm{para} \mathrm{se} \mathrm{sentar} \mathrm{e}$ aproveitar da companhia das pessoas que trabalham na casa, bem como de outros espaços para além do salão, como a biblioteca/ videoteca e a cantina.

O que é comum às sessões mediúnicas do GEC e as sessões realizadas pelo Rogério $\mathrm{H}$. Leite aqui no Rio, pelo projeto Cartas Consoladoras, é o desgaste físico e emocional causado nas pessoas. São horas esperando as leituras das psicografias, em temperaturas tórridas durante o verão carioca, sentados em qualquer espaço possível, enfrentando filas para irem ao banheiro ou comprarem alimentos e bebidas, para no final do dia essas pessoas escutarem as leituras das psicografias que provocam uma catarse emocional em todos os presentes, mesmo naqueles que não receberam as mensagens. As pessoas choram compulsivamente, desmaiam, 
o médium chora durante a leitura das psicografias. É uma comoção que se espalha. Assim como as pessoas se desesperam, elas também confortam, amparam o colega que recebeu a mensagem do familiar e está sem condições de se locomover, trazem água, oferecem seus braços e se abraçam em comunhão afetiva. Naquele momento, pessoas desconhecidas se tornam muito próximas ao compartilharem este momento catártico de manifestação das suas emoções.

Nessas sessões, em que muitas pessoas participam de diferentes regiões da cidade, o médium, em sua fala, convoca a todos e todas para trilharem o caminho do perdão e da superação, compreendendo que a vida dos entes queridos não terminou, mas permanece em outro plano e, por isso, não há motivo de revolta ou vingança. É enfatizado, tanto na fala do médium como nas mensagens, uma percepção de justiça que se contrapõe a algumas percepções compartilhadas pela sociedade.

A presença de familiares que perderam seus filhos e filhas de maneira violenta, nos centros espíritas, colocou em evidência, para essa rede, as lutas deles por justiça e a busca do conforto espiritual. Ao mesmo tempo em que essas famílias passaram a ter contato com os ensinamentos espíritas, através das palestras promovidas pelos centros, bem como de uma vasta literatura que circula atualmente pelas livrarias do país publicadas por estímulo das editoras nacionais. Diferentemente do Grupo Espiritualista Consciência (GEC), localizado na Tijuca, em que os frequentadores perderam seus familiares de formas diversas, no projeto "Amor Além da Vida" - nome das sessões no Rio de Janeiro da caravana "Cartas Consoladoras" do médium Rogério H. Leite -, parte considerável dos presentes nas sessões era de familiares de vitimas da violência urbana. Visto que os participantes eram convidados pelos organizadores do evento - pessoas que perderam seus filhos de maneira violenta -, torna-se compreensível a presença dessas famílias. O projeto, desde o começo, teve esse recorte. O símbolo do projeto, estampado na camisa dos organizadores, era o desenho do menino João Hélio, acompanhado da palavra paz. Além disso, dentre os muitos livros escritos e organizados por esse médium, um deles teve como título "Policiais de Volta", no qual ele reuniu psicografias de policiais civis e militares assassinados no Rio de Janeiro e em São Paulo juntamente com mensagens espíritas. Em uma das passagens desse livro é ressaltado o trabalho que o médium vem desenvolvendo "há anos de consolar as famílias vítimas de violência através do intercâmbio espiritual” (LEITE, 2011: 23). 
Na clivagem do projeto, e o acontecimento de casos semelhantes em outros lugares, produziu-se discursos sobre violência urbana e justiça. A relação entre espiritismo e sistema judiciário, no Brasil, é anterior ao projeto desenvolvido por Rogério, com casos de psicografias sendo aceitas como provas em processos judiciais.

Os casos em que psicografias foram aceitas como provas em julgamentos, em todos foram para inocentar o réu. No Brasil, são cinco casos de homicídio em que a decisão judicial se fundamentou em comunicações mediúnicas psicografadas por médiuns. Foram absolvidos José Divino Gomes, em Goiás, em 1976; José Francisco Marcondes de Deus, em Mato Grosso do Sul, em 1980; e Aparecido Andrade Branco no Paraná, em 1982. Há também dois casos recentes. Em uma psicografia recebida em 2004, na cidade de Ourinhos pelo médium Rogério H. Leite, "Paulinho do Estacionamento" inocenta seu concunhado, Milton dos Santos, suspeito de ser o mandante do assassinato.

O outro caso aconteceu em Viamão, no Rio Grande do Sul, em 2006. Iara Barcelos, acusada pelo assassinato do amante, Ercy Cardoso, foi absolvida pelo júri depois que a defesa apresentou uma carta psicografada por um médium que teria sido enviada pelo espírito de Ercy. Iara não quis falar sobre o caso. O advogado dela, Lúcio de Constantino, disse que a carta foi uma prova relativa, que "somada às outras firma o contexto probatório". Valter da Rosa Borges, ex-procurador de Justiça em Pernambuco (e um dos pioneiros no Brasil da parapsicologia, estudo dos fenômenos incomuns da mente humana), diz ser possível aceitar a carta psicografada como prova com base no Artigo 332 do Código Civil: "Todos os meios legais, bem como os moralmente legítimos, ainda que não especificados neste Código, são hábeis para provar a verdade dos fatos." E no Artigo 157: "O juizformará sua convicção pela livre apreciação da prova." Mas o especialista alerta que uma psicografia só pode ser válida em um processo "se reforçar outras provas ou trouxer um fato novo." (trecho retirado da reportagem de capa da Revista Isto é: “Cartas do Além” de 11 de fevereiro de 2009).

No caso da psicografia do "Paulinho do Estacionamento", como em outros, foi contestado o porquê o morto se manifestaria na carta inocentando o réu e não acusando o "verdadeiro culpado". Os médiuns argumentam que a doutrina espírita não discorre sobre vingança e justiça, mas sobre perdão e superação. Elas destacam ainda que o espírito é quem decide o quê relatar nas psicografias, sem o médium ter domínio sobre as declarações. 
A concepção de justiça do espiritismo difere em alguns aspectos da concepção jurídica, ao mesmo tempo em que em outros momentos convergem. As relações estabelecidas entre justiça divina e justiça "terrena" são inúmeras, entretanto, o que pretendo demonstrar neste trabalho é como as pessoas dialogam com múltiplas percepções de justiça existentes na sociedade. Na entrevista, o médium Rogério Leite defende que a psicografia seja usada como indício e não como prova final. A psicografia pode colaborar, como afirma Rogério H. Leite em uma reportagem, "para uma melhor avaliação dos fatos que precederam o crime. Como o médium mesmo ressalta nessa reportagem, na maioria das vezes os desencarnados querem passar mensagens de consolo e conforto para suas famílias" (reportagem do site: http://www2.uol.com.br/debate/1365/regiao/regiao04.htm, acessada no dia 27/06/2013).

Dessa maneira, esses casos demonstram que o espiritismo tangencia as discussões sobre violência urbana na medida em que familiares de pessoas vítimas da violência nas metrópoles e grandes cidades brasileiras se movimentam a partir do anseio de receberem as mensagens de seus filhos. A agência dessas pessoas, nesses casos, tem uma importância fundamental, visto que é através da presença delas nos centros que os casos passam a ser conhecidos no interior de uma rede espírita de médiuns e fiéis. São os familiares que demandam dos interlocutores mediúnicos explicações sobre as situações vividas por eles que os ajudem a superar o luto. A doutrina espírita, por outro lado, estimula essas pessoas a buscarem o caminho do perdão, da superação e da compreensão de que existem desígnios mais amplos, nem sempre de fácil acesso. Atos violentos, por mais terríveis que sejam, para a doutrina espírita, acontecem para transformar a vida de uma família, fazendo com que eles quebrem o ciclo das encarnações.

Vida e morte se entrecruzam em um emaranhado de relações estabelecidas entre familiares, consanguíneos e afins, circundados por redes de afetividade. As relações estabelecidas pelas pessoas são interpretadas à luz da doutrina espírita. Mundo material e mundo espiritual, para doutrina espírita, estão em constante relação, quase como um sendo a projeção do outro. E é justamente no diálogo entre esses dois mundos que as manifestações mediúnicas se estabelecem e, desse modo, permitem aos familiares o conhecimento de como estão seus filhos após a morte a partir de um vocabulário presente no cotidiano dessas famílias. Nos casos, por exemplo, que a morte do ente querido ocorre de maneira violenta e brusca, esse espírito vai para um hospital, no plano espiritual, para ser tratado de suas feridas 
na matéria e para também, aos poucos, ir compreendendo sua própria morte. Nesses casos, a presença de parentes desencarnados de conhecimento do espírito próximos a eles ajudam a compreender e a superar sentimentos de revolta e vingança. Em várias psicografias aparecem essas pessoas que ampararam o espírito nesse momento de passagem da vida material para a vida espiritual. Como destaca Stoll (2009):

É comum a "conscientização da morte" associar-se ao reencontro com familiares já falecidos - em geral, os avós, no caso de crianças e jovens; pais ou cônjuges, no caso de adultos. De modo geral, são estes que, de início, auxiliam a escrita da mensagem (STOLL, 2009, p.160).

Esses relatos, somados aos detalhes íntimos, de conhecimento apenas da rede familiar e afetiva próxima, ajudam os familiares que permanecem no plano material a elaborarem o luto e compreenderem que nem sempre as explicações se encontram no plano em que eles estão, mas em outras esferas da experiência espiritual. Para o espiritismo, se a pessoa morre de forma muito violenta na sua última vida material, as explicações podem estar em vidas passadas.

Essa religiosidade é fruto da permanente relação entre o Mundo Visível e o Mundo Invisível, em que este engloba aquele a partir de uma relação hierárquica. Como descreve Maria Laura Viveiros de Castro Cavalcanti (1983), há uma relação de complementaridade entre os dois mundos, ordenada a partir de dois eixos: sincrônico e diacrônico. O eixo diacrônico corresponde às encarnações que representam à trajetória cósmica do Espírito até atingirem o grau de Espíritos superiores. "A vida de um Espírito é, por conseguinte, um encadeamento de passagens entre os dois mundos, de encarnações, desencarnações e reencarnações" (CAVALCANTI, 1983, p. 35). O eixo sincrônico remete à comunicação espiritual entre Espíritos encarnados (Mundo Visível) e Espíritos desencarnados (Mundo Invisível). A pessoa como o Espiritismo a concebe é composta por três elementos: o corpo, o perispírito e o Espírito. O homem possui uma natureza dupla: corpo e alma. O espírito quando se une a matéria no corpo humano é denominado de alma. "Alma e corpo estão unidos por um laço semimaterial, o perispírito. O perispírito e o fluido universal são os mediadores nas passagens e comunicações entre os dois mundos" (CAVALCANTI, 1983, p. 43). É através da concepção de pessoa dessa religião que se torna viável a comunicação entre o Mundo Visível e o Mundo Invisível, ou seja, entre Espíritos encarnados e Espíritos 
desencarnados, permitindo a continuidade entre os estágios de vida e de morte pelas diversas formas de mediunidade, entre elas a psicografia e psicofania ${ }^{6}$.

Na trajetória da busca de perfeição pelos espíritos, eles escolhem se, onde, como, quando irão encarnar. Desse modo, não é fato incomum que um espírito encarne em uma mesma família e que a ligação estabelecida entre esses familiares e os fortes vínculos que os conectam sejam justificados pela convivência em inúmeras vidas, passadas e presentes. Se em algumas religiões há um conflito entre o ethos religioso e a construção da pessoa no seio da família, o espiritismo promove a comunhão de todos os membros "familiares" - tanto da família construída a partir da vivência religiosa, como da de origem - inserindo todos no projeto maior de evolução da espécie humana. A própria reunião desses diferentes espíritos na vida presente é explicada por vivências comuns em vidas passadas. A relação entre as pessoas que comungam, no presente, espaços similares de sociabilidade é entrelaçada pela ideia de carma - como ressalta Evangelina Mazur (2006), "termo emprestado do hinduísmo e quer dizer uma espécie de carga existente em todas as pessoas, trazidas de vidas anteriores, que pode se manifestar por meio de doenças ou conflitos interpessoais" (MAZUR, 2006, p.162). Além disso, a máxima de Alan Kardec "O Acaso não Existe" e a tensão existente no interior dessa cosmologia entre livre-arbítrio e missão fornecem as representações simbólicas para a leitura dos vínculos estabelecidos entre as pessoas na vida presente.

Em seu texto "Dos mortos e sua volta: biografia e família na literatura espírita", Sandra Jacqueline Stoll (2009) questiona os argumentos de que, na modernidade ocidental, os cultos aos mortos se tornaram privados e ritualizados, com os vivos recusando a possibilidade da morte e se esquecendo dos "seus mortos". O interesse pelo espiritismo e pelas psicografias, segundo a autora, veio por meio do questionamento dessa argumentação, tão fundamentada analiticamente por Ariès (1990) passando por Lévi-Strauss (1986), Certeau (1994) e Elias (2001).

[...] A escolha se justifica por se tratar de doutrina religiosa cuja prática ritual se funda em múltiplas formas de produção do contato entre vivos e mortos. Essas práticas são frequentemente públicas, portanto, permitem investigar os modos pelos quais, nesse contexto particular, se criam formas coletivas de compartilhamento da experiência da morte e seus significados (STOLL, 2009, p. 154).

\footnotetext{
${ }^{6}$ Para uma descrição mais detalhada desse sistema religioso ver CAVALCANTI, Maria Laura Viveiros de Castro. O mundo invisível. Cosmologia, sistema ritual e noção de pessoa no espiritismo. Rio de Janeiro: Zahar, 1983.
} 
É possível ampliar essa perspectiva trazida pela pesquisadora Sandra Stoll (2009) dando prosseguimento as suas reflexões. O espiritismo, ao criar formas coletivas de compartilhamento da experiência da morte, cria também formas coletivas de experiência de vida. Dessa percepção surgiu o interesse pelo meu tema de doutorado quando ao redor de uma mesa farta, de bolos e doces, vi um grupo de familiares de pessoas que perderam seus filhos e filhas pela violência urbana na cidade do Rio de Janeiro se confraternizar e falar de seus filhos com uma naturalidade como se esses estivessem vivos, no sentido material da existência espiritual segundo a teoria das encarnações. Meu espanto aumentou quando esses começaram a me narrar que seus filhos que não se conheceram, durante a vivência material dos seus espíritos, se encontravam no mundo invisível e mandavam recados para os pais de seus novos amigos. Assim, o Thiago - filho da Francilene - que não conheceu a Ludmila - filha da Zoraide - mandava mensagem para a Zoraide dizendo que a Ludmila estava bem. Assim, como o André ${ }^{7}$ - filho do Sr. Orlando - relatava em uma das suas psicografias que estava próximo de Ludmila, no Mundo Invisível, mas que ambos moraram muito próximos no bairro do Grajaú, no Rio de Janeiro, quando ambos estavam encarnados. Ao redor dessa mesa na casa dos pais do João Hélio $^{8}$ no Méier estavam os pais e a avó do João Hélio, o casal Francilene e Diriadson, Zoraide, Sr. Orlando discutindo a primeira vinda do médium Rogério H. Leite para o Rio com o seu projeto "Cartas Consoladoras". A este grupo inicial se juntaram, posteriormente, outros familiares de vítimas da violência que atuaram ativamente nos movimentos de familiares de vítimas da violência na cidade do Rio de Janeiro, estado do Rio de Janeiro.

Por acompanhar esse grupo há cerca de quatro anos, pude perceber que, cada um, a sua maneira, incorporaram parte da doutrina espírita em suas trajetórias de vida, narrando os seus processos de superação da dor e da aceitação do perdão. Aos poucos, essa rede espírita, nas psicografias e no trabalho do tempo, assumiu práticas descritas por eles como sendo projetos pessoais de superação da dor, com discursos de adesão aos pressupostos da Cultura da Paz. Um exemplo disso é a trajetória da família do menino João Hélio. Em matérias divulgadas próximas da morte do menino, a postura da família era de revolta e vingança.

\footnotetext{
7 Policial civil assassinado em um assalto.

${ }^{8} \mathrm{O}$ caso João Hélio teve ampla repercussão nos meios de comunicação. O menino de 6 anos, morreu após ser arrastado pelas ruas por diversos bairros do Rio de Janeiro, preso ao carro pelo cinto de segurança. Após o carro da família ser assaltado, sua mãe e irmã conseguiram sair e os assaltantes não permitiram que a mãe retirasse a criança do carro. A mãe, a irmã e o menino estavam vindos de um centro espírita em Oswaldo Cruz, retornando para a casa da família no Méier.
} 
Envoltos em um clima de clamor por vingança - difundido por boa parte da população brasileira, com comentários estampados nas reportagens dos principais jornais do país -, os pais do menino defendiam transformações na legislação penal, a partir de mudanças no código penal como: a redução da maioridade penal e a pena de morte. Algumas propostas chegaram a ser defendidas pela Associação Brasileira de Magistrados da Infância e da Juventude, como apresentada na reportagem do Jornal do Brasil Menor infrator mais tempo preso, do dia 13 de fevereiro de 2007 (em anexo), em que os magistrados apresentaram a proposta de ampliação de três anos para cinco anos o tempo que um jovem infrator pode ficar em regime fechado em uma instituição sócio-educativa.

Percepções diferenciadas sobre justiça - divina e terrena - aparecem nos discursos desses familiares de vítimas em muitos momentos da minha pesquisa de campo. Nesse aspecto, o caso João Hélio traz questões que atravessam os demais casos, mesmo com as particularidades de cada um. A relação estabelecida entre sistema judiciário e espiritismo é central na compreensão desse caso, como de outros. Assim como os familiares do João Hélio se distanciaram gradativamente das discussões das reformas no direito penal e passaram a se dedicar ao espiritismo, outros familiares seguiram a mesma trajetória. Em período próximo ao ocorrido, os pais do menino participaram de diversas manifestações públicas no Rio, e em outros estados, exigindo leis mais severas para os criminosos. Atualmente, eles estão distantes de todas as manifestações políticas de familiares de vítimas da violência urbana do Rio de Janeiro e, o caso, é citado por terceiros sem a presença deles. A família participa apenas de sessões espíritas - como a sessão em que a mãe, a irmã e o menino vinham no dia da morte doe João Hélio. No trabalho que desenvolveram durante dois anos junto com o médium Rogério Leite, em que cediam a casa da família no Méier para a realização das sessões de psicografias, se dedicaram com afinco a promoção dos pressupostos da doutrina espírita: a superação da dor e do luto, trilhando o caminho da compaixão - conceito que também é caro à doutrina espírita.

O vídeo do pai do João Hélio em reportagem veiculada no programa de televisão aberta "Mais Você" elucida o argumento que trago: http://www.youtube.com/watch?v=feaBXVY-SYI. No vídeo, Elson ressalta que "o grande objetivo da vida é a prática do bem”. Com voz serena, ele destaca ainda que a saudade física sempre permanecerá, mas que, a partir das sessões de psicografias, quando nelas ele consegue 
visualizar o sorriso no rosto das pessoas que receberam a mensagem de seus familiares, percebeu que isso não tem preço, é impagável. Segundo ele, "na medida em que você consegue enxergar a morte de uma outra forma, não como fim, mas como uma mudança, uma mudança de planos, você já vislumbra um outro universo. Você já olha de uma maneira de que existe uma continuação, que você precisa se tornar uma pessoa melhor.Você precisa mudar. Você precisa principalmente despertar para a vida". Vida aqui compreendida como uma sucessão de encarnações e reencarnações, como o ciclo de desenvolvimento do espírito até o momento no qual ele se torna parte da perfeição divina e não retorna mais ao mundo material, visto como local de sofrimento e dor. Essa perspectiva ampliada da existência humana é o que fundamenta a busca do perdão, uma vez que a limitação do homem impede que compreenda todos os desígnios divinos. Os diversos planos de existência de um espírito se sobrepõem na construção da trajetória pessoal de um espírito, segundo os ensinamentos da doutrina, se entrelaçando no encadeamento das múltiplas vivências pessoais.

As mensagens psicografadas veiculam narrativas sobre justiça e perdão e, desse modo, convidam os pais a superarem os sentimentos de vingança. Um exemplo está presente no trecho da psicografia de Ludmila:

"Mãe amada se você quiser continuar a sua luta por justiça, que faça, mas não deixe que essa luta seja maior que a oportunidade de você ser feliz. Não faça dessa bandeira a viga mestra de sua vida porque esta de nada serviu em tua caminhada, o desafio que enfrentaste, Eu lhe peço que se queres justiça, seja justa com você mesma e aproveite a sua vida [...] Você cultiva essa ferida diariamente com ódio e rancor e não permite que ela cicatrize. A paz não chega a ti porque aduba essa chaga de ausência de fé. Existe sim uma justiça que ainda não conseguimos entender, mas sim há uma justiça muito maior" (trecho retirado da psicografia, por mediação do médium Fábio Figueiredo).

As narrativas, reconhecidas como sendo verídicas pelos pais, articulam sobre diferentes conceitos de justiça: a terrena, etérea; e a divina, que rege o mistério do ciclo das encarnações. E, nesse ponto, as concepções de justiça presentes nas psicografias convergem com as noções de justiça compartilhadas pelos tribunais brasileiros. As psicografias só foram aceitas em juízo nos casos em que inocentavam réus e, em nenhuma vez, foram utilizadas para condenar ou punir. Na medida em que esses exemplos concordam com a validação de um determinado projeto de paz - em que não há espaço para a revolta e vingança, apenas para 
a conciliação e o perdão -, as provas espirituais tornam-se provas positivadas, tendo a veracidade atestada pelo sistema judiciário.

Desse modo, podemos falar em projetos de pacificação, governo das almas e razões do Estado que são, ao mesmo tempo, políticas e religiosas. Projetos distintos de governo das condutas que se convergem na consolidação de conceitos de justiça. É interesse ressaltar que, nos casos em que psicografias foram aceitas, o religioso não é visto como corrompendo a racionalidade. Ao mesmo tempo, a positividade da lei não é questionada. Os arranjos, nessas situações, legitimam formas de governo - de si e dos outros.

Para os pais e mães que constituem a rede de sociabilidade na qual pesquiso, a aceitação e superação ocorreram a partir das psicografias de seus filhos, pela leitura dos textos espíritas, pela presença nas sessões em centros de diversas regiões do país, e pela própria leitura particular da doutrina espírita. Durante esses anos de pesquisa, pude perceber como eles foram gradativamente abandonando o discurso de revolta e vingança, assumindo, a partir de uma leitura particular, os conceitos da cosmologia espírita, tais como: missão, caridade e perdão. O governo de si, das suas condutas, foi elaborado a partir da apropriação desses conceitos espíritas, vinculados às sociabilidades construídas e compartilhadas nos dois planos: material e espiritual, pelas psicografias.

O que pretendi, neste artigo, foi demonstrar como conceitos de justiça, elaborados por diferentes esferas, se relacionam na construção de narrativas sobre a violência urbana no Rio de Janeiro. Projetos religiosos e políticos, com aspirações distintas, se sobrepõem na elaboração de um ideário de conciliação de conflito em que a revolta e a vingança dão espaço ao perdão e a compaixão no processo de pacificação das almas. São apontamentos do meu trabalho de campo que surgem como pistas analíticas de leitura das relações estabelecidas pelos projetos políticos e religiosos de enfrentamento da violência urbana, inseridos em um projeto macropolítico de adesão à Cultura da Paz.

\section{Referências Bibliográficas:}

ÀRIES, Philippe. O homem diante da morte. Rio de Janeiro: Francisco Alves, 1990. 
BIRMAN, Patrícia. \& LEITE, Márcia. "Apresentação". In. Um Mural para a Dor: movimentos cívico-religiosos por justiça e paz. (Org.) LEITE, Márcia e BIRMAN, Patrícia. Porto Alegre: Editora da UFRGS, 2004.

CAVALCANTI, Maria Laura Viveiros de Castro. O Mundo Invisível. Cosmologia, Sistema Ritual e Noção de Pessoa no Espiritismo. Rio de Janeiro: Zahar Editores, 1983.

CERTEAU, Michel de. A escrita da história. Rio de Janeiro: Forense Universitária, 1994.

ELIAS, Norbert. A solidão dos moribundos. Rio de Janeiro: Jorge Zahar, 2001.

FOUCAULT, Michel. Segurança, Território, População: curso dado no College de France 1977-1978. Aula de 1o. de março de 1978 e Aula de 08 de março de 1978. São Paulo: Martins Fontes, 2008. (pp.253-340)

LEITE, Rogério H. Policiais de Volta. Lorena: 2011.

LÉVI-STRAUSS, Claude. Tristes trópicos. Lisboa: Presença, 1986.

MAZUR, Evangelina Maria. "Família e laços familiares em um contexto espiritualista". In: DUARTE, Luiz Fernando D. Família e religião. Rio de Janeiro: ContraCapa, 2003.

STOLL, Sandra Jacqueline. "Dos mortos e sua volta: biografia e família na literatura espírita”. Debates do NER. Porto Alegre: UFRGS, IFCH, PPGAS, 1997 - semestral.

\title{
RELIGION AS EVIDENCES ON JUDGMENTS ANS SUPPORT BY THE JUDICIAL SYSTEM: POLITICAL-RELIGIOUS RELATIONS BETWEEN VICTMS OF URBAN VIOLENCE FAMILY MEMBERS IN RIO DE JANEIRO
}

\begin{abstract}
This study aims to describe the political-religious links established by relatives of victims of violence in the city of Rio de Janeiro, through the interfaces between spiritualism and politics regarding the construction of discourses on social suffering. In the cases of the aforementioned relatives, the search for justice for their deceased children, who were transformed into public cause, is linked to the pilgrimage of these parents to spiritual centers in search of written spiritual messages of their children. The maintenance of communication, besides the affective contacts, is also seen as the opportunity to clarify the events related to the deaths of the children - and thereby understand them - by using the written spiritual texts as possible proofs in trials. The dialogues between the judiciary system
\end{abstract}


and the spiritualistic philosophy, promoted by these families, allow us to understand the actions of these families fighting for justice, solace and subjective adherence to the Culture of Peace.

KEYWORDS: Spiritualism. Judiciary. Psichography. Urban Violence

\section{Anexo}
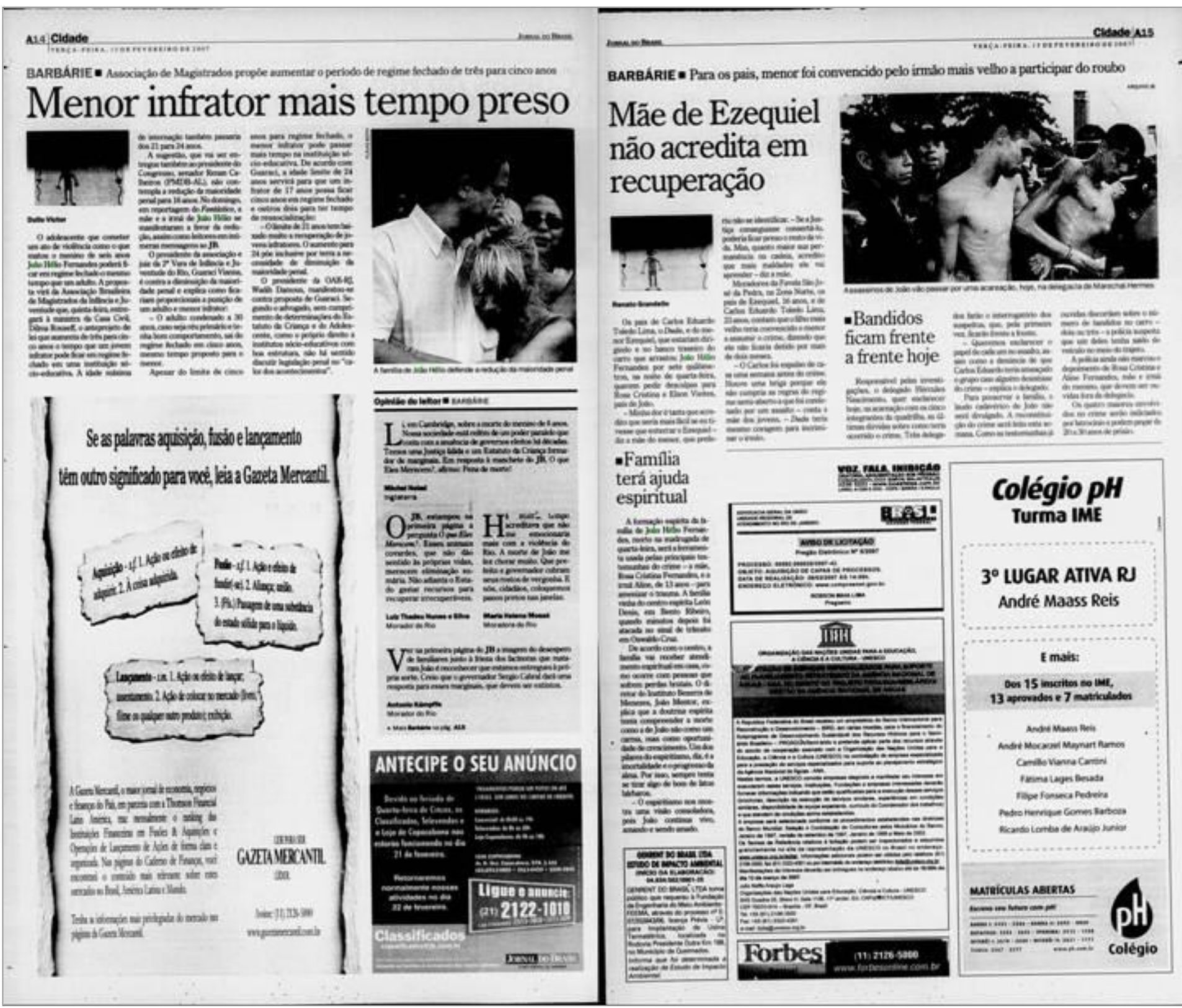